Supporting Information

\title{
Electroactive Oligoaniline-Containing Self-Assembled Monolayers for Tissue Engineering Applications
}

\author{
Yi Guo ${ }^{\mathrm{a}}$, Mengyan Li ${ }^{\mathrm{b}}$, Andreas Mylonakis ${ }^{\mathrm{a}}$, Jingjia Han ${ }^{\mathrm{b}}$, Alan G.MacDiarmid ${ }^{\mathrm{c}}$, Xuesi \\ Chen $^{\mathrm{d}}$, Peter I. Lelkes ${ }^{\mathrm{b} *}$, and Yen Wei ${ }^{\mathrm{a} *}$ \\ ${ }^{a}$ Department of Chemistry, $b$ School of Biomedical Engineering \& Engineering, Drexel \\ University, Philadelphia, PA 19104, USA. \\ ${ }^{c}$ Department of Chemistry, University of Pennsylvania, PA 19104, USA \\ ${ }^{d}$ Changchun Institute of Applied Chemistry, Chinese Academy of Science, P.R.China \\ 130022 \\ *E-mail: weiyen@drexel.edu and pilelkes@drexel.edu
}




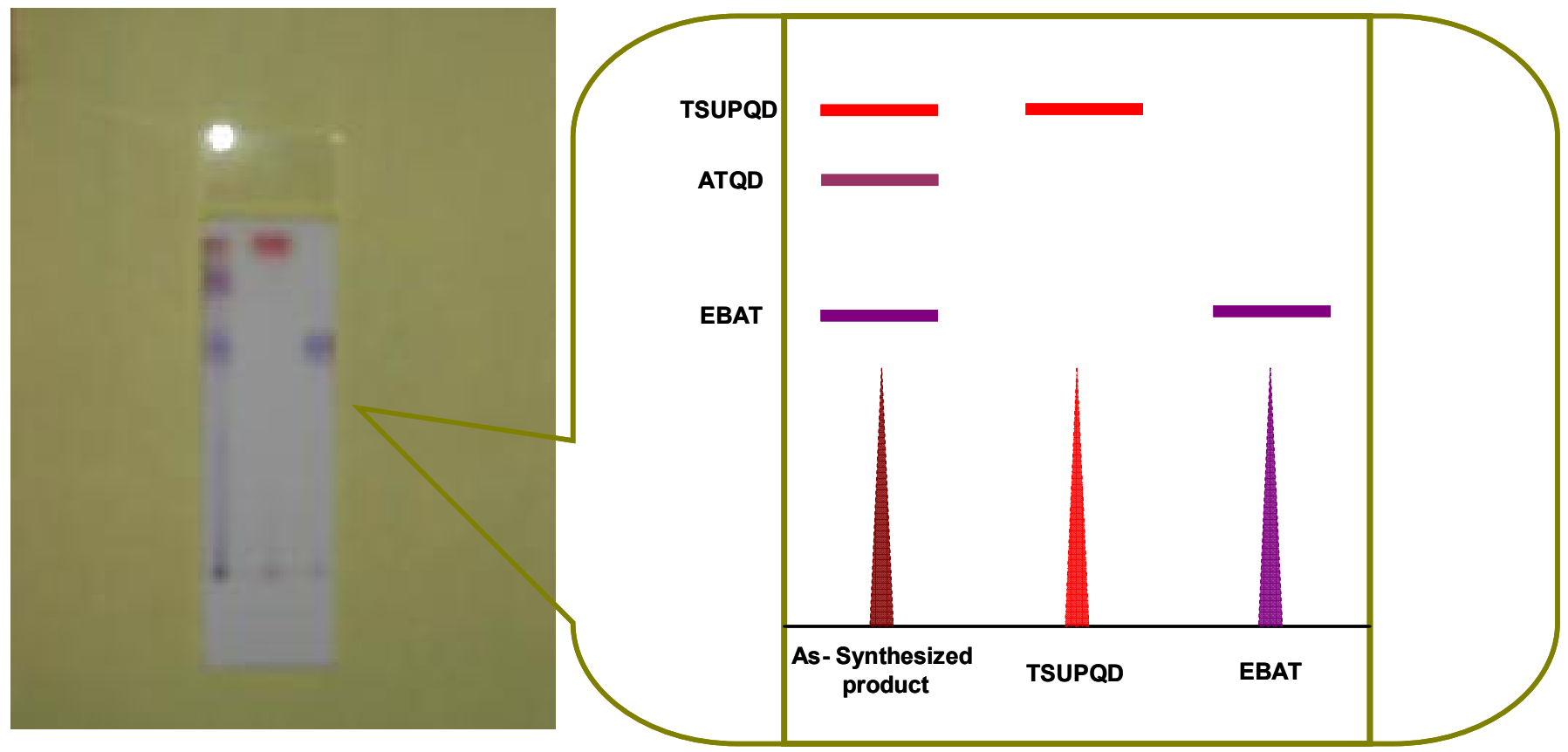

Figure S1. Separation of as-synthesized sample via thin layer chromatography. 


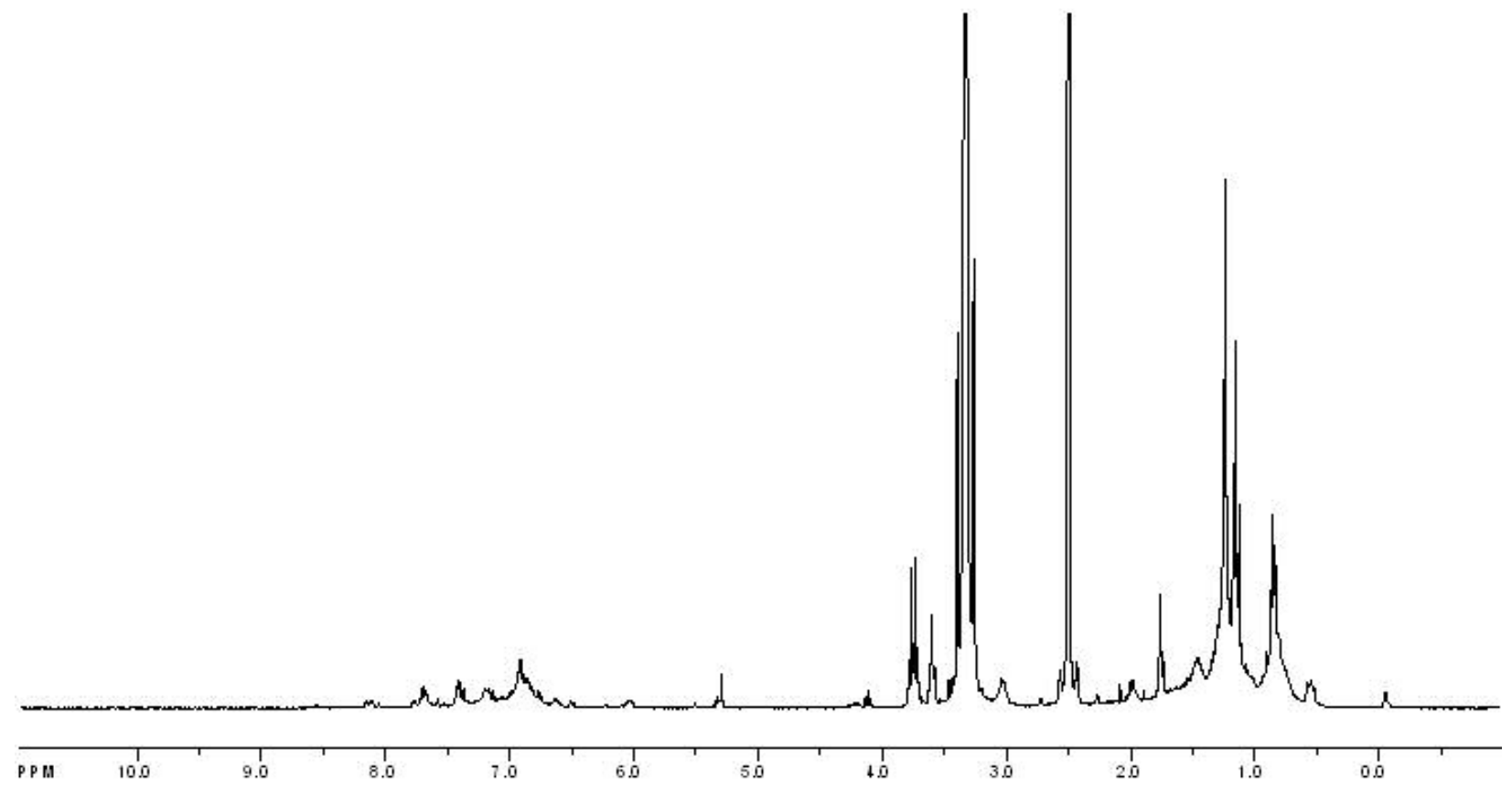

Figure S2. ${ }^{1} \mathrm{H}-\mathrm{NMR}$ spectra for ATQD 


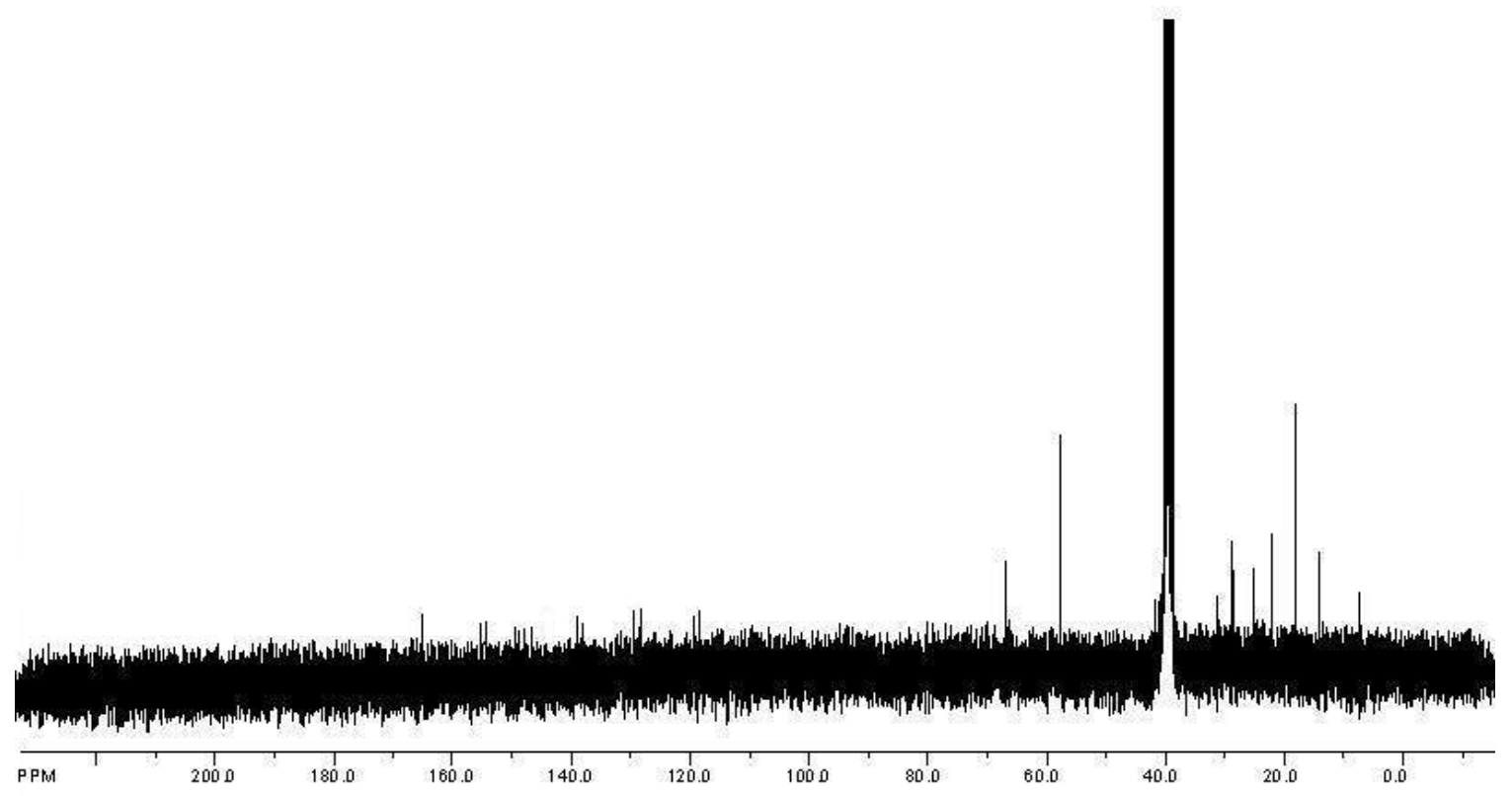

Figure S3. ${ }^{13} \mathrm{C}$-NMR spectra for ATQD 


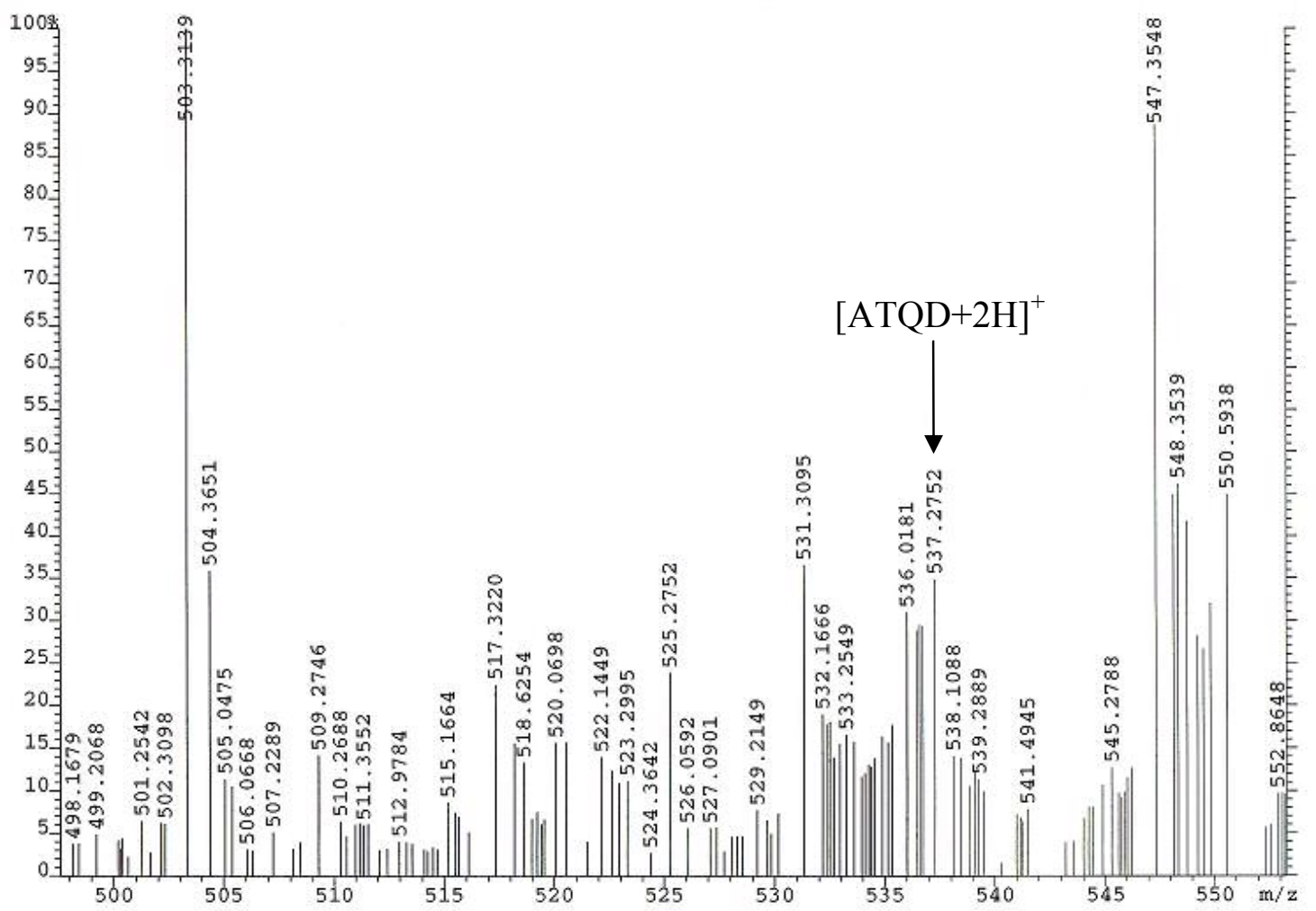

Figure S4. Mass spectra for ATQD in high resolution 


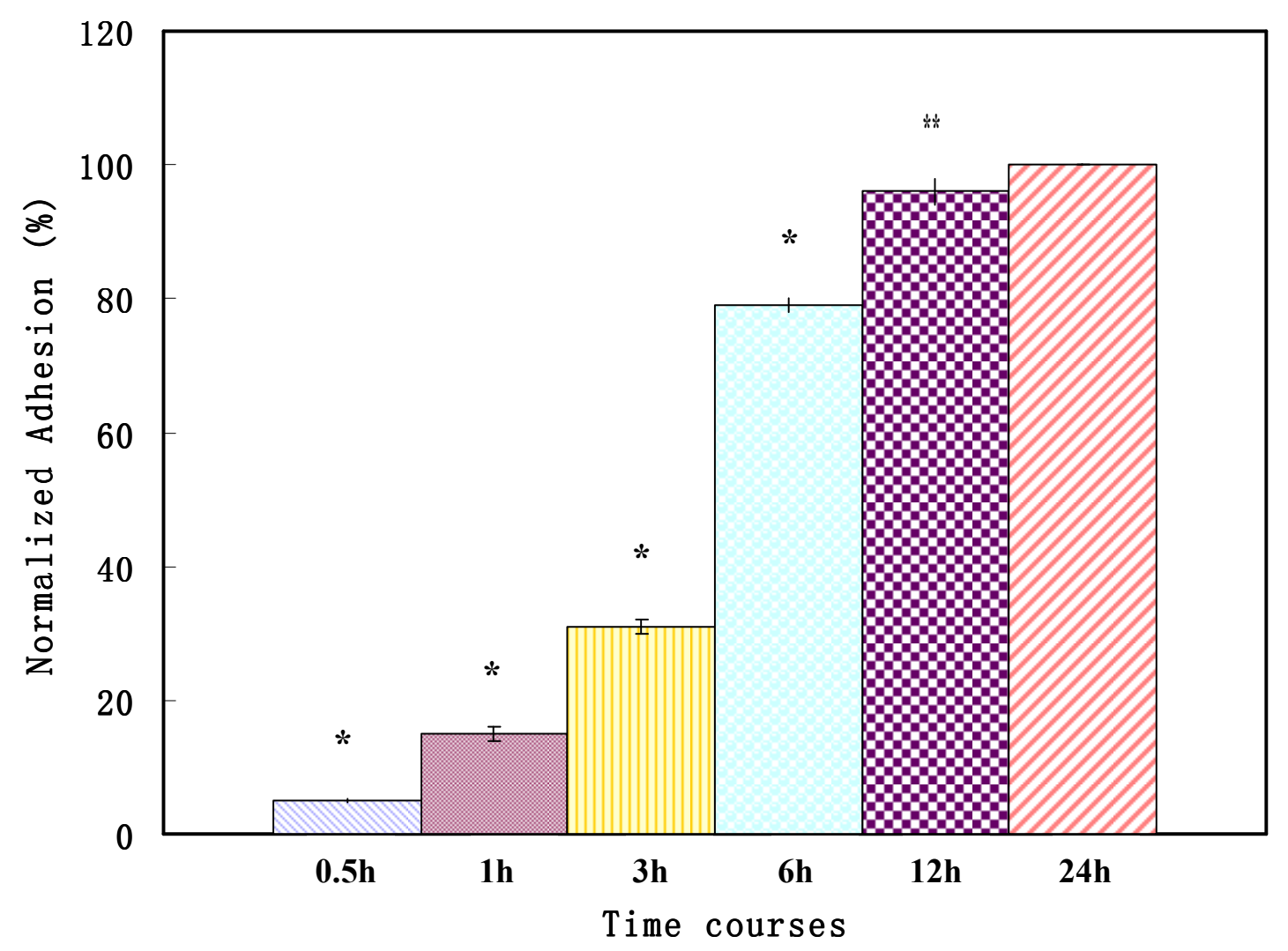

Figure S5. The increment of attached cells on ATQD-RGD via AB assay and the data were normalized to the $\mathrm{AB}$ fluorescence reading at $24 \mathrm{~h}$. Data are expressed as means $\pm \mathrm{SD}, \mathrm{n}=3$. *: $\mathrm{p}<0.01 ; * *: \mathrm{p}<0.05$, values are significantly different from those at $24 \mathrm{~h}$. 


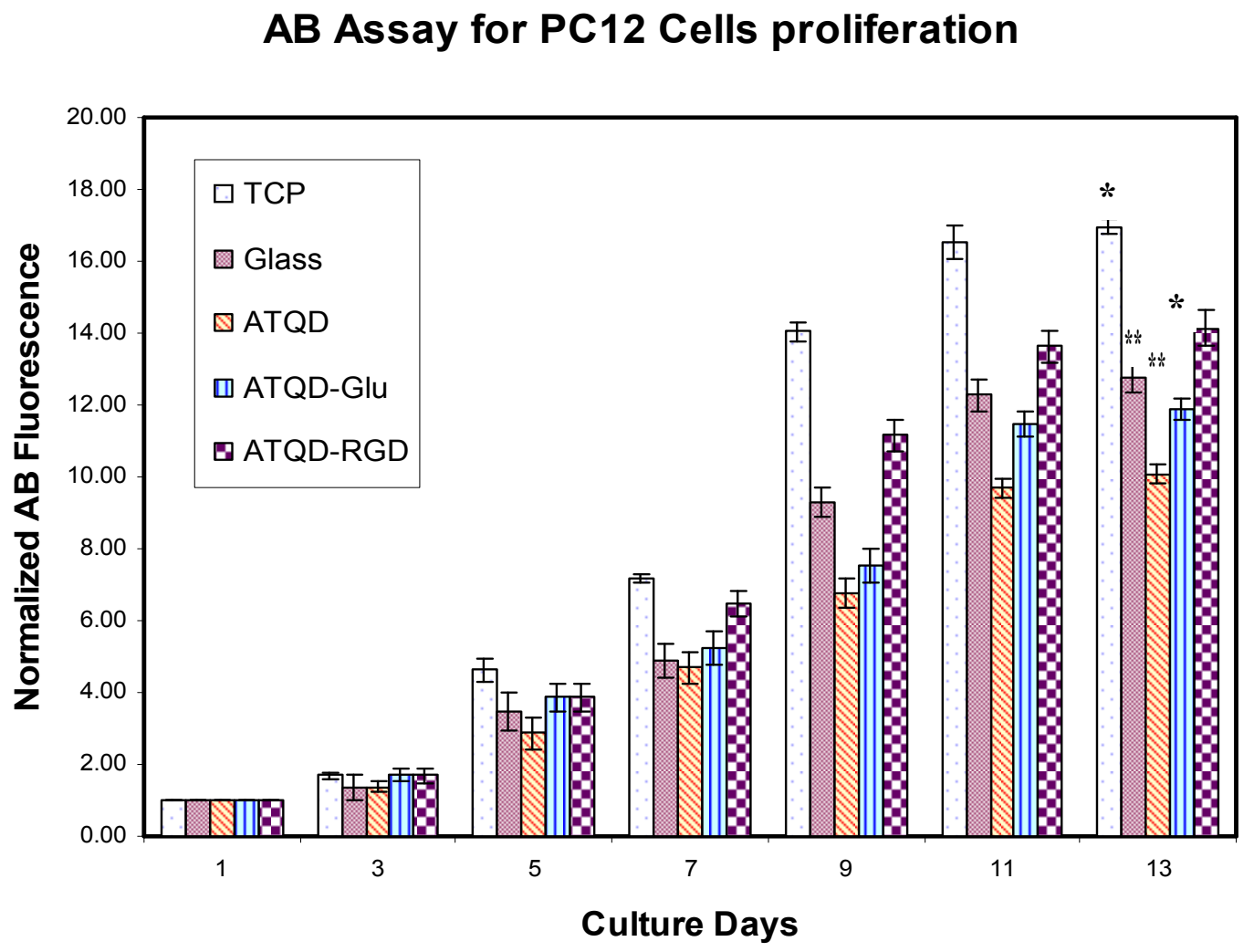

Figure S6. PC12 cell proliferation on various substrates over a 13 day time course. Cell proliferation / metabolic activity were evaluated using the Alamar Blue (AB) Assay. The data were normalized to the $\mathrm{AB}$ fluorescence reading at day 1 . Data are expressed as means $\pm \mathrm{SD}, \mathrm{n}=3$. *: $\mathrm{p}<0.01 ; * *: \mathrm{p}<0.05$, values are significantly different from those on ATQD-RGD substrates at day 13. 


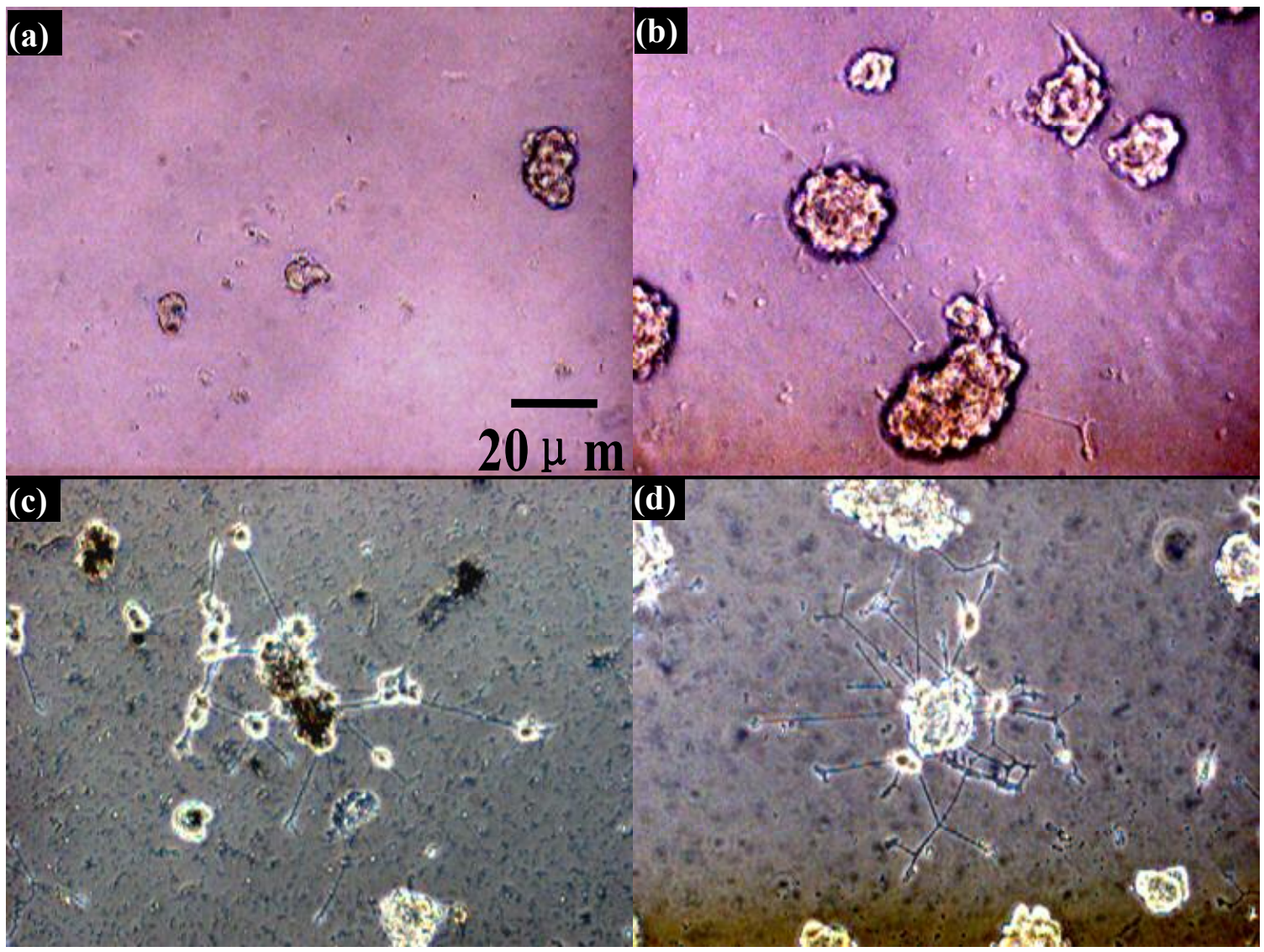

Figure S7. Phase contrast images of PC12 cells morphology for (a) TCP (b) TCP+NGF (c) ATQD-RGD and (d) ATQD-RGD + NGF in day 6. 
S8
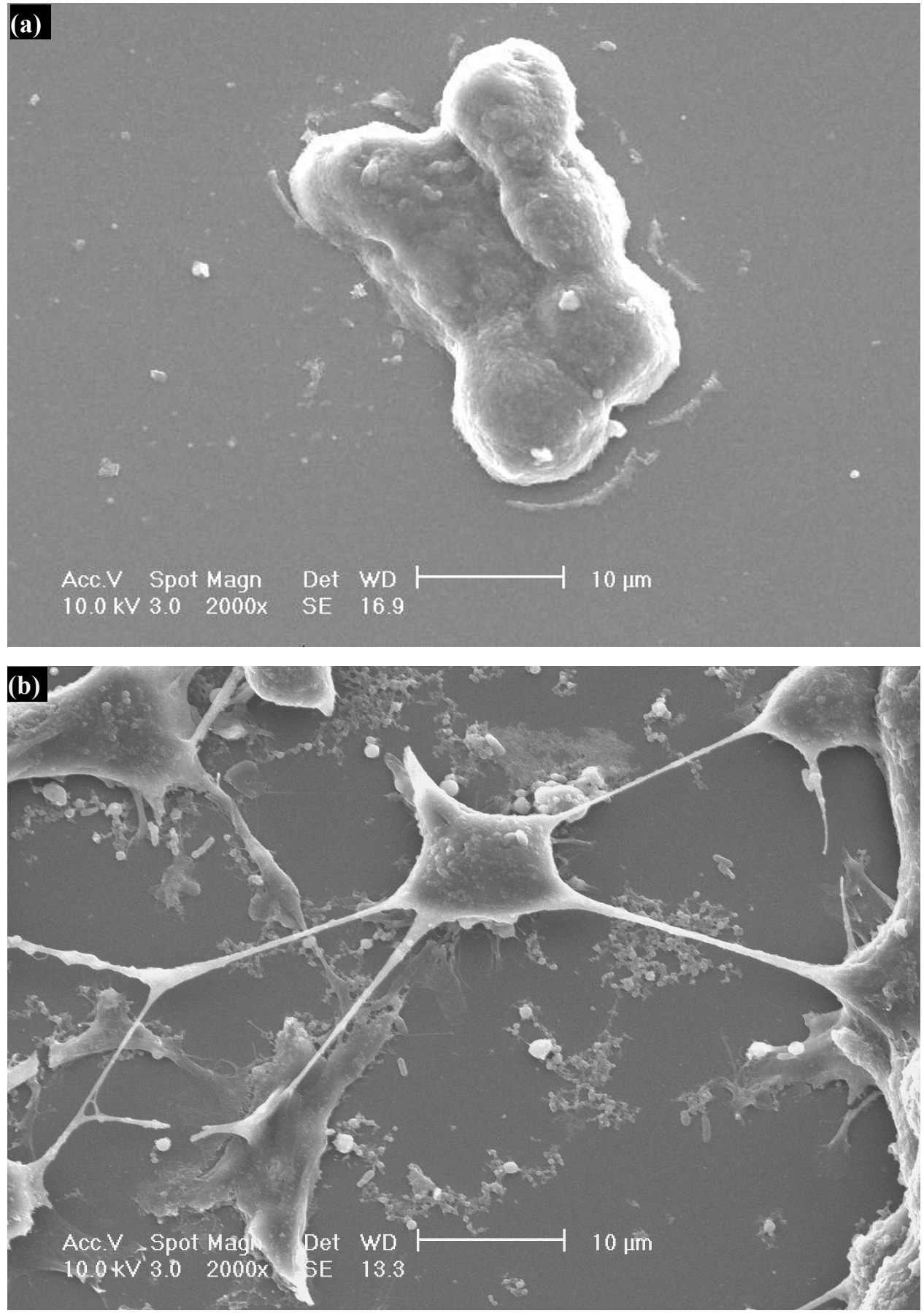

Figure S8. SEM micrographs of differentiated PC12 cells on (A) glass substrates and (B) ATQD-RGD substrates in day 10. 
S9.

$$
\text { FT-IR spectra }
$$

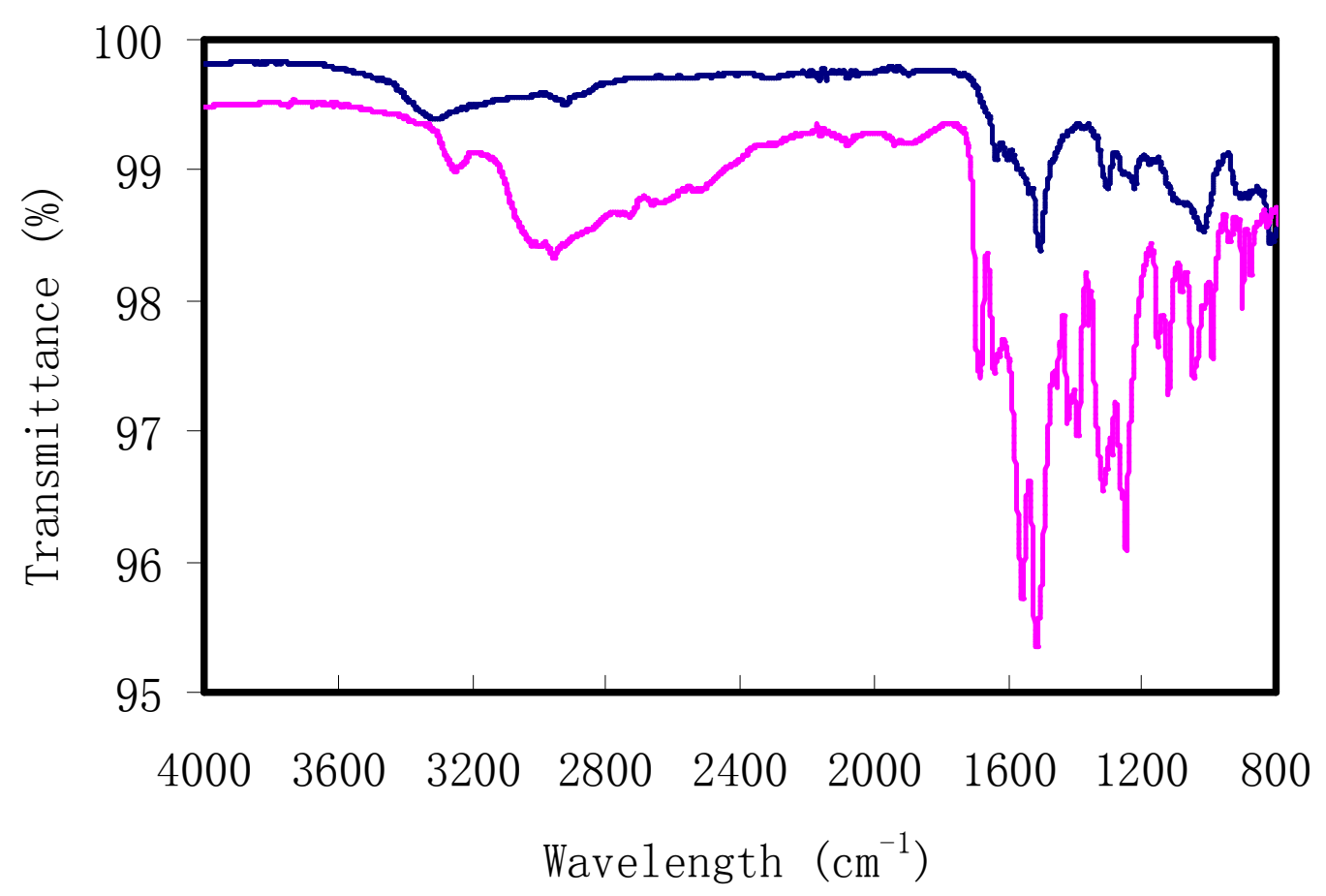

Figure S9. IR spectra of ATQD and ATQD-RGD monolayers

We also conducted FTIR to show the characteristic peaks of the amino acids in RGD to further prove the attachment of RGD onto the ATQD surfaces. The shift of the broad vibrational bands from the original ca. 3400 $\mathrm{cm}^{-1}$ to ca. $3300 \mathrm{~cm}^{-1}$ is associated with the conversion of the aromatic amine $\left(-\mathrm{NH}_{2}\right)$ in the aniline trimer into the imine (-NH) group and incorporation of the amide (-NH-CO-) moieties from RGD oligopeptide. Importantly, the presence of the stronger carbonyl band at ca. $1700 \mathrm{~cm}^{-1}$ also supports the new appearance of amide groups from covalently grafted amino acids. 
S10.

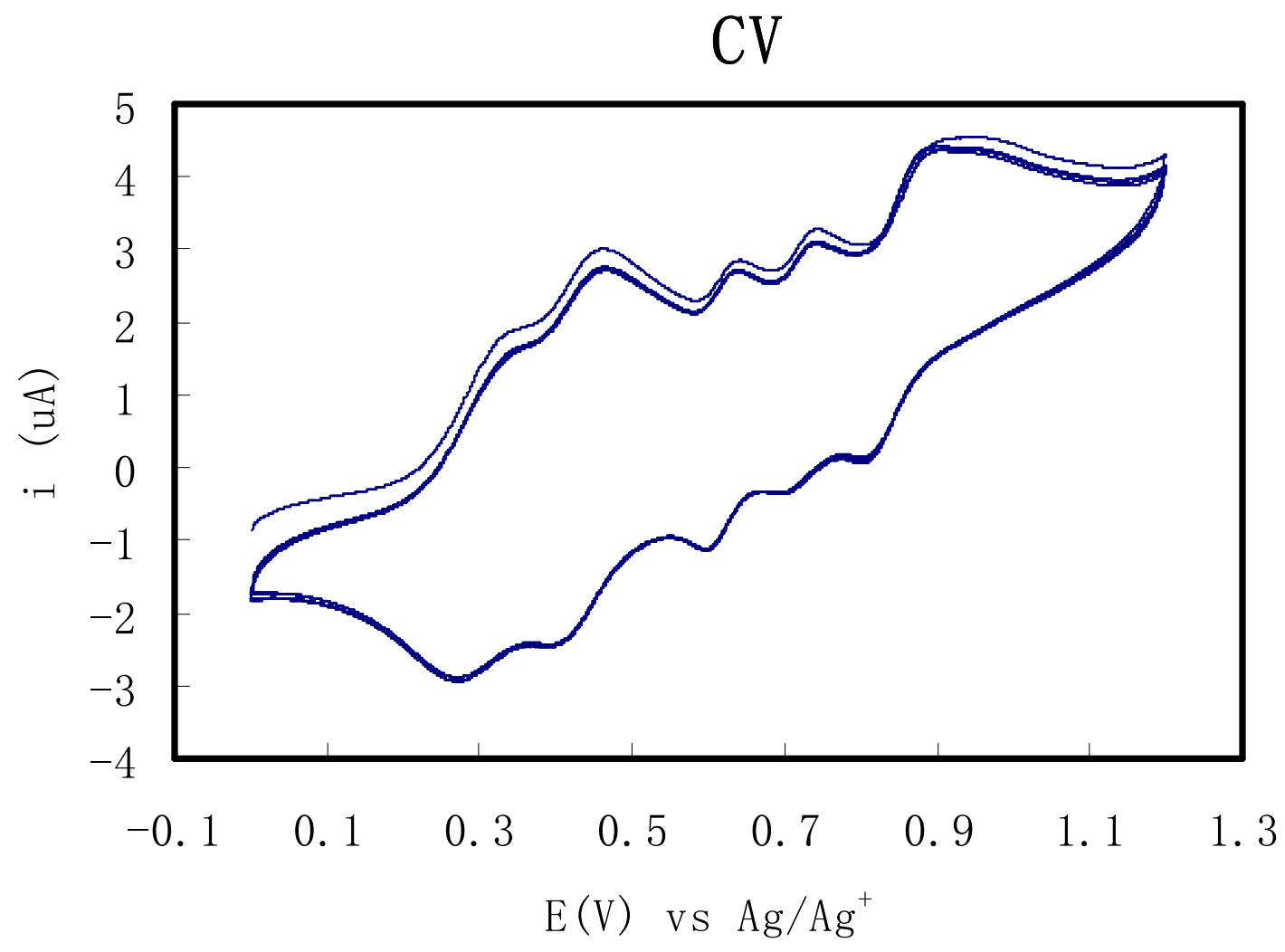

Figure S10. Cyclic voltammogram of ATQD with ten cycles

Ten cycles of $\mathrm{CV}$ were conducted, demonstrating the unique long-term stability of the electroactivity of ATQD. Conductivity measurements using the four-probe method were also conducted, yielding a conductivity of ATQD of about $5 * 10^{-4}$ $\mathrm{s} / \mathrm{cm}$. 
S11.

Table S1. Elemental composition

for emeraldine salt of ATQD ${ }^{*}$ deduced from mass spectra

\begin{tabular}{lllllllll}
\hline Exp.Mass & Calc.Mass & $\mathrm{mDa}$ & $\mathrm{PPM}$ & $\mathrm{C}$ & $\mathrm{H}$ & $\mathrm{N}$ & $\mathrm{O}$ & $\mathrm{Si}$ \\
\hline 537.2752 & 537.2771 & 1.9 & 3.6 & 28 & 39 & 5 & 4 & 1 \\
\hline
\end{tabular}

"Exp. Mass, experimental mass; Calc. Mass, calculated mass; mDa, absolute error in milidaltons; PPM, relative error in parts per million. 